\section{|||||||||||||||||||||||||||||||||||||||||||||||||||||||||||||||||||.}

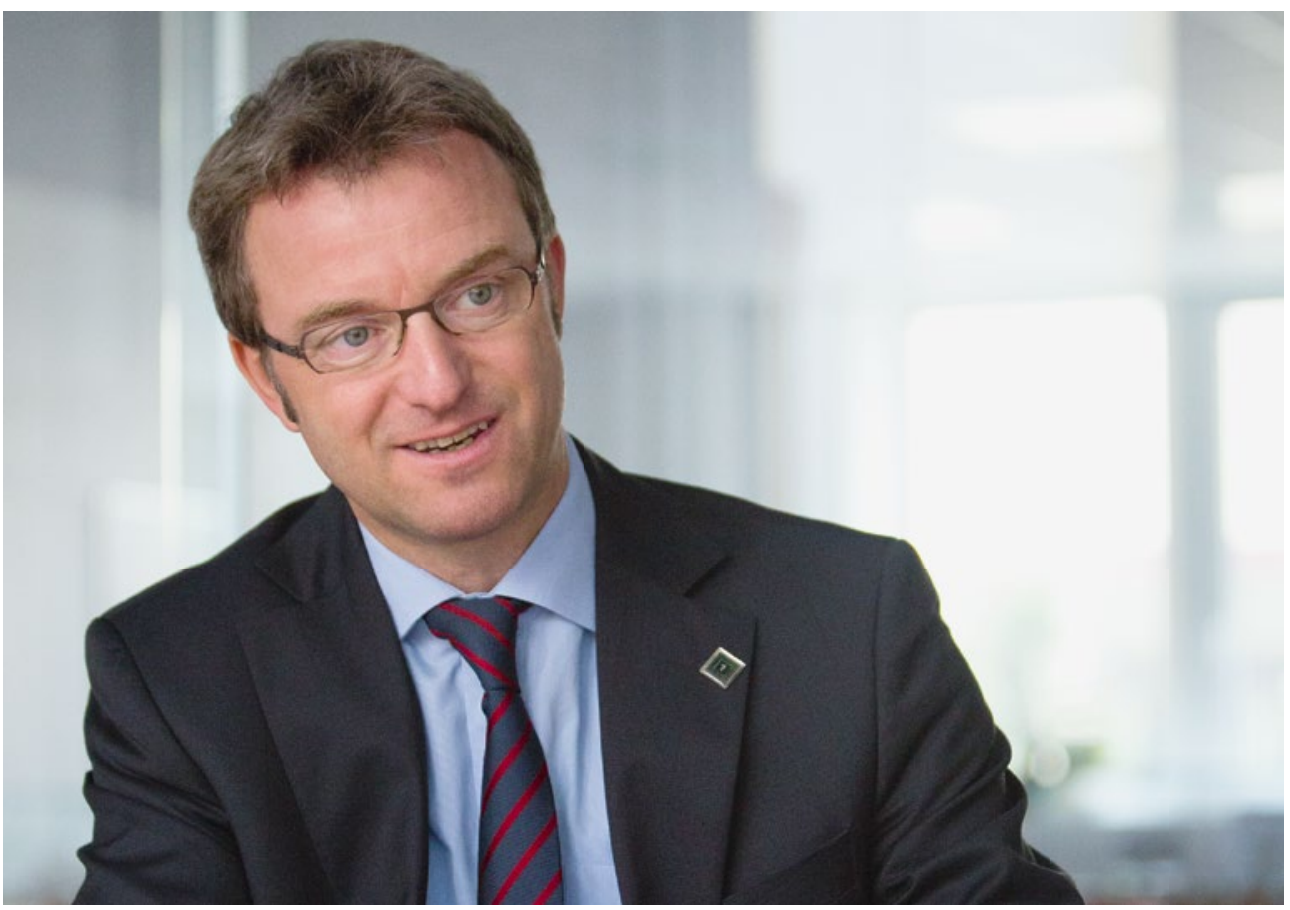

Stephan Lehmann

Quality Director - EMEA

bei Freescale in München

\title{
Herausforderung Hardware
}

Die nächsten zehn Jahre werden für die Automobilelektronik atemberaubende Veränderungen bringen. Das Potenzial ist riesig, die Risiken sind es auch. Daher ist es eine besondere Ehre und Verpflichtung, als einziger Vertreter der Komponentenindustrie einen Beitrag im Wissenschaftlichen Beirat der ATZelektronik zu leisten, um das Wissen in der Industrie bezüglich anstehender Veränderungen in der Halbleiterwelt so zu aktivieren, dass sich die Waage in den kommenden Jahren in die richtige Richtung neigt.

Auf der Consumer Electronics Show 2015 wurde mit rekordverdächtigem Aufwand dem Endverbraucher gezeigt, dass sich das Automobil zum elektronischen Technologieträger entwickelt. Das Automobil als komplexester Knoten im „Internet of Tomorrow“, auf dem Weg zum autonomen Fahren, als Lösung von Umwelt- und Mobilitätsherausforderungen in Megacities. Eine Vision, für die man sich begeistern kann, allerdings nur mit den richtigen Weichenstellungen.

So wird heute noch die Wichtigkeit von Hardware gegenüber Software unterschätzt. Beides muss paritätisch behandelt werden. Denn viele der benötigten Hardware-Komponenten wurden für andere Marktsegmente entwickelt und noch nie im Automobil eingesetzt. Wir brauchen deswegen neue Lösungen für die drahtlose Vernetzung der Fahrzeuge und Sicherheitslösungen, die das Automobil vor Angriffen von außen schützen. Wir benötigen enorme Datenbandbreiten und Rechner-Performance, die dramatisch über heutigen im Automobil liegt - all das integriert mit Sicherheitskonzepten, die eine zuverlässige Funktion über einen erhöhten Temperaturbereich, bei niedrigstem Energieverbrauch über die Lebensdauer der Fahrzeuge sicherstellt. Und das Ganze zu vertretbaren Kosten - obwohl die Automobilstückzahlen eher klein sind im Vergleich mit anderen Märkten.

Die ZVEI-Arbeitsgruppe Consumer Components in Safe Automotive Applications hat herausgearbeitet, dass es mehr als 60 Faktoren gibt, die für automobile Anwendungen wichtig sein können und nicht notwendigerweise zum Beispiel von Consumer-Komponenten geleistet werden. Vereinfacht gesprochen kann man diese Unterschiede in zwei Gruppen bündeln: Eigenschaften der Komponenten und Fähigkeiten der Lieferanten selbst. Beide sind über Jahrzehnte gewachsen und nicht trivial. Die Länge der Reise und die Gefahren auf dem Weg zum Ziel des autonomen Fahrens hängen sehr stark davon ab, wie wir den Startpunkt in beiden Dimensionen wählen.

Damit wird die Halbleiterkompetenz der Entscheider beim OEM zu Beginn der Reise zu einem entscheidenden Erfolgskriterium der Anbieter zukünftiger Mobilität. Daher wünsche ich mir im Interesse der deutschen Automobilwirtschaft, dass alle Entscheider eines erkennen: Das Fundament des autonomen Fahrens in sicheren, langlebigen Fahrzeugen hoher Qualität ist die „elektronische Hardware“, die technischen Herausforderungen sind immens und nur gemeinsam in einer tragfähigen und langfristigen Partnerschaft über die Lieferkette hinweg zu meistern. Die Reise beginnt jetzt. 